\title{
PREDIKSI KEBANGKRUTAN BERDASARKAN METODE ALTMAN Z-SCORE (studi kasus perusahaan makanan dan minuman yang terdaftar pada BEI 2011-2016)
}

\author{
Chicha Lestari $^{1}$, Muh. Halim ${ }^{2}$, Junaidi ${ }^{3}$, \\ ${ }^{1}$ )Prodi Manajemen, Sekolah Tinggi Ilmu Ekonomi (STIE) Muhammadiyah Palopo \\ ${ }^{2,3}$ )Prodi Akuntansi, Sekolah Tinggi Ilmu Ekonomi (STIE) Muhammadiyah Palopo
}

\begin{abstract}
Abstrak
Penelitian ini bertujuan untuk mengetahui dan menganalisis prediksi kebangkrutan perusahaan makanan dan minuman yang terdaftar pada Bursa Efek Indonesia periode 2011-2016 menggunakan metode Alman Z-Score. Metode analisis data yang digunakan dalam penelitian ini adalah metode Altman Z-Score menggunakan lima rasio yaitu Working Capital to Total Asset (X1), Retained Earning to Total Asset (X2), Earning Before Interest and Tax to Total asset (X3), Market Value of Equity to Book Value Of Total Liabilities (X4), Sales to Total Asset. Hasil dari penelitian ini adalah dari tahun 2011-2016 terdapat tujuh perusahaan makanan dan minuman berada pada kondisi keuangan yang sehat, tiga perusahaan makanan dan minuman berada pada kondisi grey area ( daerah abu-abu), dan satu perusahaan makanan dan minuman berada pada kondisi bangkrut. Kata Kunci : Kebangkrutan, Perusahaan Makanan dan Minuman, Metode Altman Z-Score.
\end{abstract}

\section{PENDAHULUAN}

Perusahaan makanan dan minuman merupakan salah satu industri yang selalu mengalami tingkat persaingan yang tinggi di Indonesia dan merupakan salah satu sektor perusahaan mempunyai peranan yang sangat penting dalam pertumbuhan ekonomi di Indonesia dan selalu meningkat dalam beberapa kurun waktu terakhir. Salah satu penyebab umun terjadinya kebangkrutan pada perusahaan manufaktur adalah turunnya tingkat penjualan, penurunan penjualan itu bisa menyebabkan terjadinya penurunan pendapatan perusahaan dan berdampak pada turunnya laba. Apabila perusahaan tidak mampu mendeteksi hal tersebut lama kelamaan perusahaan akan merugi dan perusahaan akan bangkrut. Tandatanda lainnya yang dapat dilihat dari sebuah perusahaan yang mengalami kesulitan keuangan antara lain yaitu adanya penurunan pendapatan, laba, total aset dan harga pasar saham. Seperti pada 3 sampel sektor industri makanan dan minuman dibawah ini :

Jurnal manajemen keuangan ... Tahun 20182 Tabel 1.1 Data Total Aset 3 sampel Perusahan makanan dan minuman Tahun PT. Mayora Indah Tbk PT. Nippon Indosari Corpindo, Tbk PT. Siantar Top, Tbk.

\begin{tabular}{|c|c|l|c|}
\hline $\begin{array}{c}\text { Tah } \\
\text { un }\end{array}$ & $\begin{array}{c}\text { PT. Mayora } \\
\text { Indah }\end{array}$ & $\begin{array}{l}\text { PT. } \\
\text { Nippon } \\
\text { Indosari } \\
\text { Corpindo }\end{array}$ & $\begin{array}{c}\text { PT. Siantar } \\
\text { Top, Tbk. }\end{array}$ \\
\hline 2011 & 6.599 .845 .5 & 759.136 .9 & 2.180 .516$. \\
& 33.32 & 18.50 & 519.05 \\
\hline 2012 & 8.302 .506 .2 & 120.494 .4 & 2.420 .793$. \\
& 41.93 & 68.12 & 382.02 \\
\hline 2013 & 9.710 .223 .4 & 182.268 .9 & 1.470 .059$. \\
& 54.0 & 04.71 & 394.89 \\
\hline 2014 & 10.291 .108$. & 214.289 .4 & 1.700 .204$. \\
& 029 & 27.62 & 093.89 \\
\hline 2015 & 11.342 .715$. & 270.632 .3 & 1.919 .568$. \\
& 686 & 63.70 & 037.17 \\
\hline 2016 & 12.922 .421$. & 291.964 .0 & 2.336 .411$. \\
& 859.1 & 85.87 & 494.94 \\
\hline
\end{tabular}

Sumber : www.idx.co.id

Berdasarkan tabel diatas menunjukkan bahwa perkembangan aset pada PT. Mayora Indah, Tbk periode 2011-2016 mengalami peningkatan yang cukup baik dari tahun ketahun. PT. Nippon Indosari Corpindo,Tbk menunjukkan perkembangan aset pada periode 2011-2016 mengalami kondisi yang kurang baik, seperti pada tabel diatas menunjukkan PT. Nippon Indosari Corpindo mengalami fluktuasi pada periode 2012. PT. Siantar Top, Tbk menunjukkan perkembangan aset pada tabel 
diatas mengalami fluktuasi pada periode 20122013. Untuk mengatasi atau meminimalisir terjadinya kebangkrutan diperusahaan, pihak manajemen harus melakukan pengawasan terhadap kondisi keuangan perusahaan dengan menggunakan alat yang dapat mendeteksi potensi kebangkrutan perusahaan. Alat ini dilakukan dengan melakukan analisis prediksi kebangkrutan yang diukur melalui laporan keuangan perusahaan. Hal ini dilakukan untuk mengetahui tingkat kebangkrutan yang dimiliki perusahaan dari tahun ke tahun dan dapat digunakan sebagai peringatan awal bagi perusahaan yang diprediksi bangkrut dan pihak manajemen perusahaan dapat memperbaiki kinerja perusahaannya dimasa akan datang.

\section{METODE PENELITIAN}

Penelitian dilakukan dengan cara penelitian sekunder yaitu mengambil data atau informasi melalui akses internet ke website Bursa Efek Indonesia masing- masing Perusahaan Makanan dan Minuman di Indonesia. Waktu Penelitian dilaksanakan April sampai Mei 2018. Dalam penelitian ini jenis data yang digunakan adalah data kuantitatif. Adapun sumber data yang digunakan adalah data primer. Data Primer adalah data yang bersumber dari situs web resmi Bursa Efek Indonesia www.idx.co.id.

Populasi dalam penelitian ini adalah seluruh Perusahaan Makanan dan Minuman, sedangkan dalam penentuan jumlah sampel dengan metode Purposive Sampling adalah metode pengambilan sampel yang ditetapkan dengan beberapa kriteria. Kriteria yang ditetapkan dalam pengambilan sampel menggunakan Purposive Sampling adalah sebagai berikut :

1. Perusahaan tersebut tercatat sebagai Perusahaan Makanan dan Minuman di Bursa Efek Indonesia Periode 2011-2016.

2. Perusahaan tersebut melaporkan laporan keuangan atau ringkasan laporan keuangan di website Bursa Efek Indonesia www.idx.co.id, sehingga sampel yang menjadi di gunakan adalah sebanyak 11 perusahaan.

Untuk menghitung dan menganalisis Analisis data dalam penelitian dilakukan dengan menggunakan Altman menemukan lima jenis rasio keuangan yang dapat dikombinasikan untuk melihat perbedaan antara perusahaan yang bangkrut dan yang tidak bangkrut dengan menggunakan rumus metode Altman Z-Score sebagai berikut (Hanafi, 2016:656) :

$\mathrm{Z}=1,2(\mathrm{X} 1)+1,4(\mathrm{X} 2)+3,3(\mathrm{X} 3)+0,6(\mathrm{X} 4)$ $+1,0(X 5)$

\section{PEMBAHASAN}

Tabel 4.6.1

Hasil Z-Score Pada Perusahaan

Makanan dan Minuman tahun

2011

\begin{tabular}{|l|l|l|l|l|l|l|l|}
\hline $\begin{array}{c}\text { Kode } \\
\text { Perusah } \\
\text { Aan }\end{array}$ & X1 & X2 & X3 & X4 & X5 & $\begin{array}{l}\text { Z- } \\
\text { Sco } \\
\text { re }\end{array}$ & $\begin{array}{l}\text { Hasil } \\
\text { Anali } \\
\text { sis }\end{array}$ \\
\hline AISA & 0,28 & 0,04 & 0,17 & 0,49 & 0,50 & 1,48 & $\begin{array}{l}\text { Bang } \\
\text { krut }\end{array}$ \\
\hline CEKA & 0,36 & 0,24 & 0,53 & 4,05 & 1,50 & 6,68 & Sehat \\
\hline DLTA & 0,83 & 1,05 & 0,96 & 0,87 & 20,0 & 23,7 & Sehat \\
\hline ICBP & 0,44 & 0,34 & 0,59 & 4,03 & 1,27 & 6,67 & Sehat \\
\hline INDF & 0,26 & 0,69 & 3,00 & 1,10 & 0,85 & 5,90 & Sehat \\
\hline MLBI & - & 0,57 & 1,85 & 6,57 & 1,52 & 10,4 & Sehat \\
\hline MYOR & 0,41 & 1,05 & 0,30 & 1,57 & 1,43 & 4,75 & Sehat \\
\hline ROTI & 0,06 & 0,50 & 0,66 & 0,95 & 1,07 & 3,24 & Sehat \\
\hline SKLT & 0,25 & 0,13 & 0,66 & 0,64 & 1,61 & 3,28 & Sehat \\
\hline STTP & 0,16 & 0,53 & 0,20 & 1,22 & 1,09 & 3,19 & Sehat \\
\hline ULTJ & 0,16 & 0,45 & 0,23 & 0,26 & 0,96 & 4,05 & Sehat \\
\hline
\end{tabular}

Sumber : Data sekunder diolah Mei 2018

Tabel 4.6.2

Hasil Z-Score Pada Perusahaan Makanan dan Minuman tahun 2012

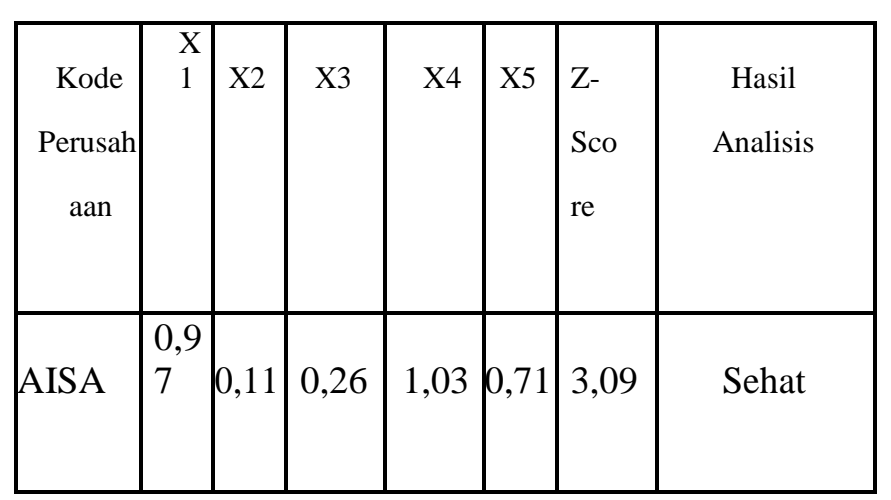




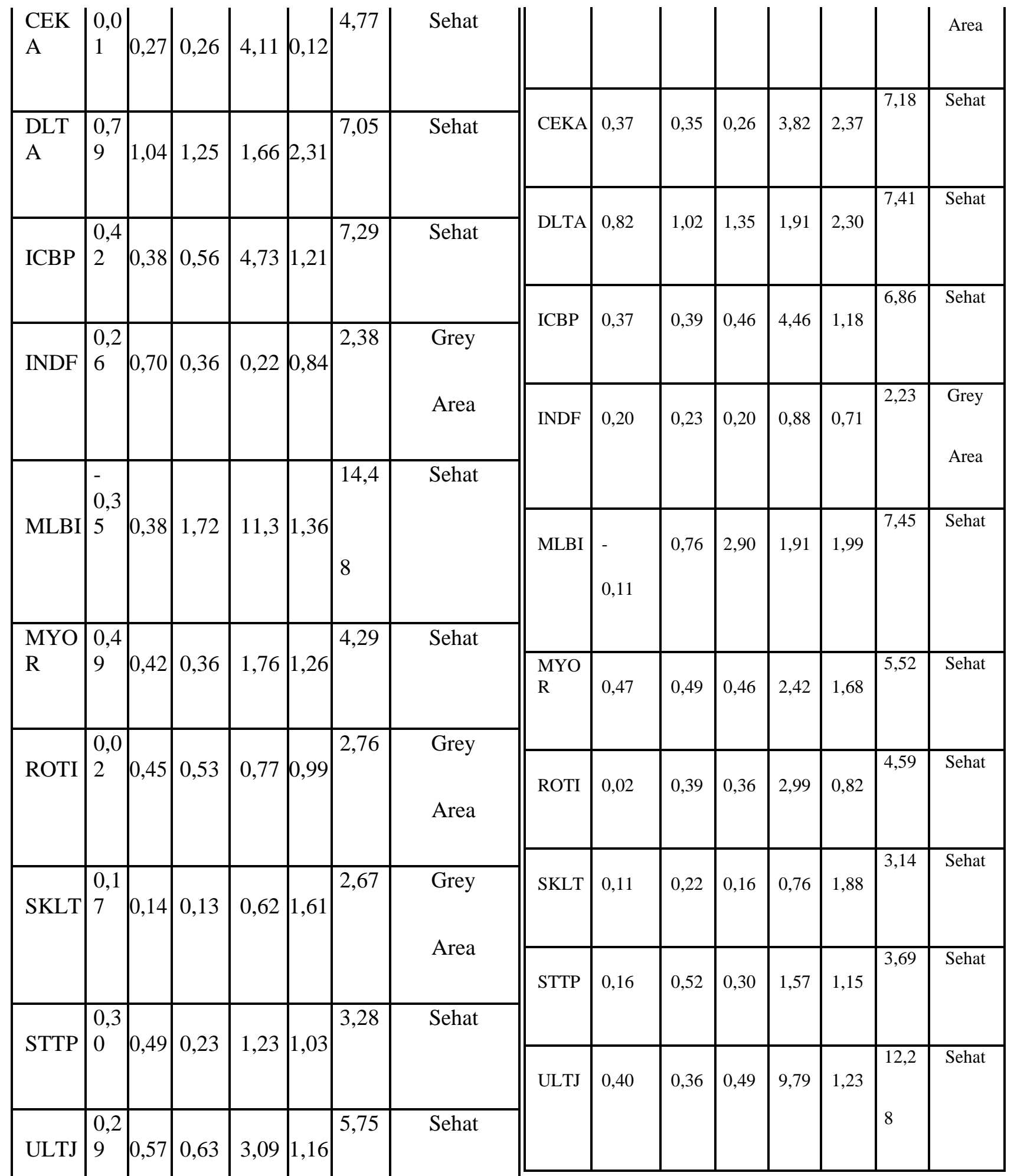

Sumber : Data sekunder diolah Mei 2018

Sumber : Data sekunder diolah Mei 2018

Tabel 4.6.3

Hasil Z-Score Pada Perusahaan

Makanan dan Minuman tahun 2013

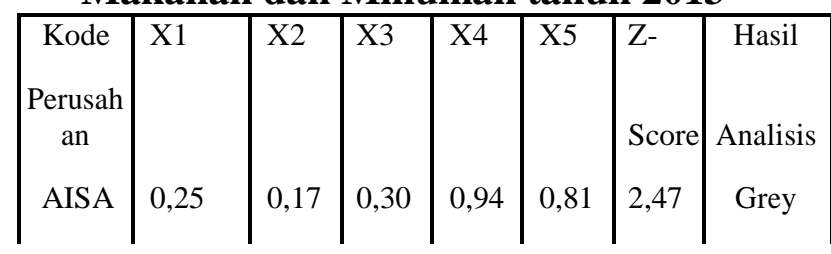

Tabel 4.6.

Hasil Z-Score Pada Perusahaan

Makanan dan Minuman tahun 2014

\begin{tabular}{|c|c|c|c|c|c|c|c|}
\hline $\begin{array}{c}\text { Kode } \\
\text { Perusahaa } \\
\mathrm{n}\end{array}$ & $\mathrm{X} 1$ & $\mathrm{X} 2$ & $\mathrm{X} 3$ & $\mathrm{X} 4$ & $\mathrm{X} 5$ & $\mathrm{Z}-$ & Hasil \\
AISA & 0,41 & 0,17 & 0,20 & 1,03 & 0,71 & 2,52 & Grey \\
& & & & & & & Area
\end{tabular}


ISSN : 2339-1510

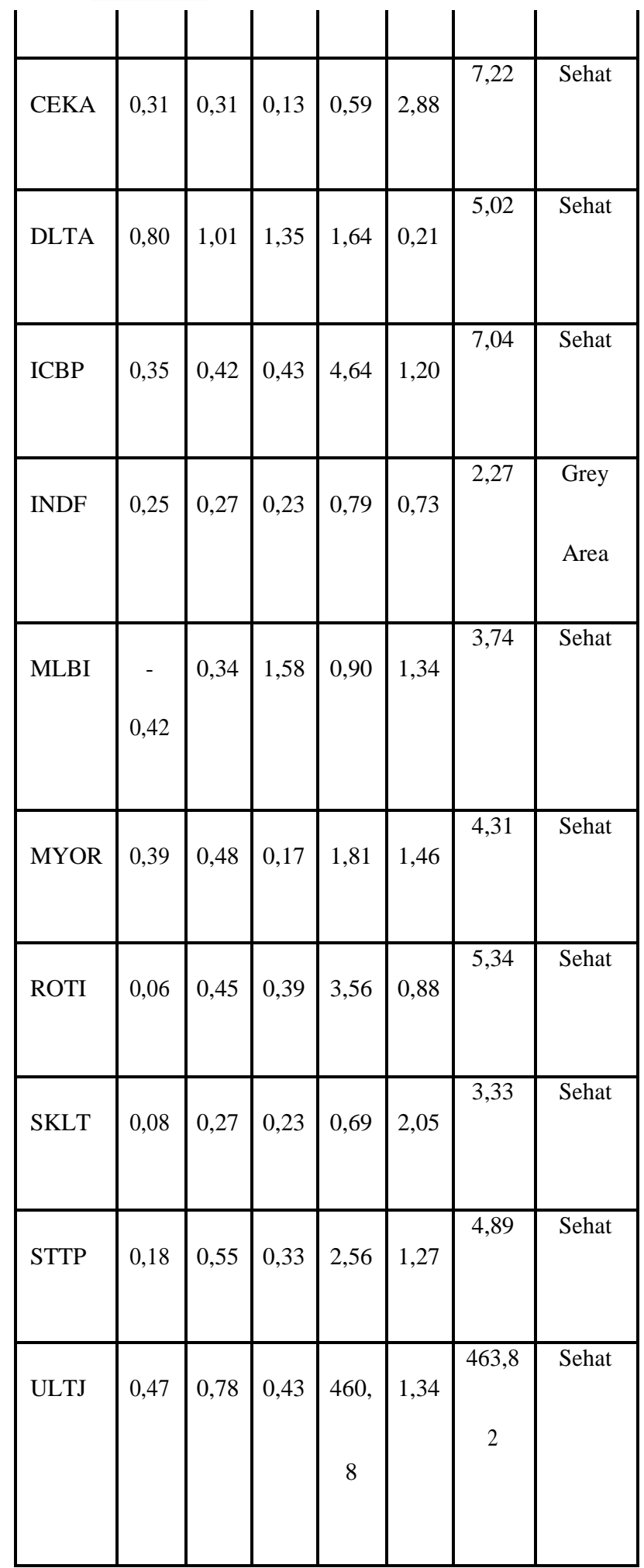

Sumber : Data sekunder diolah Mei 2018

Tabel 4.6.5

Hasil Z-Score Pada Perusahaan Makanan dan Minuman tahun 2015

\begin{tabular}{|c|c|c|c|c|c|c|c|}
\hline $\begin{array}{c}\text { Kode } \\
\text { perus } \\
\text { ahaan }\end{array}$ & $\mathrm{X} 1$ & $\mathrm{X} 2$ & $\mathrm{X} 3$ & $\mathrm{X} 4$ & $\mathrm{X} 5$ & Z- Score & $\begin{array}{c}\text { Hasil } \\
\text { Analis }\end{array}$ \\
AISA & 0,23 & 0,18 & 0,16 & 0,46 & 0,66 & 1,69 & Bangkrut \\
\hline
\end{tabular}

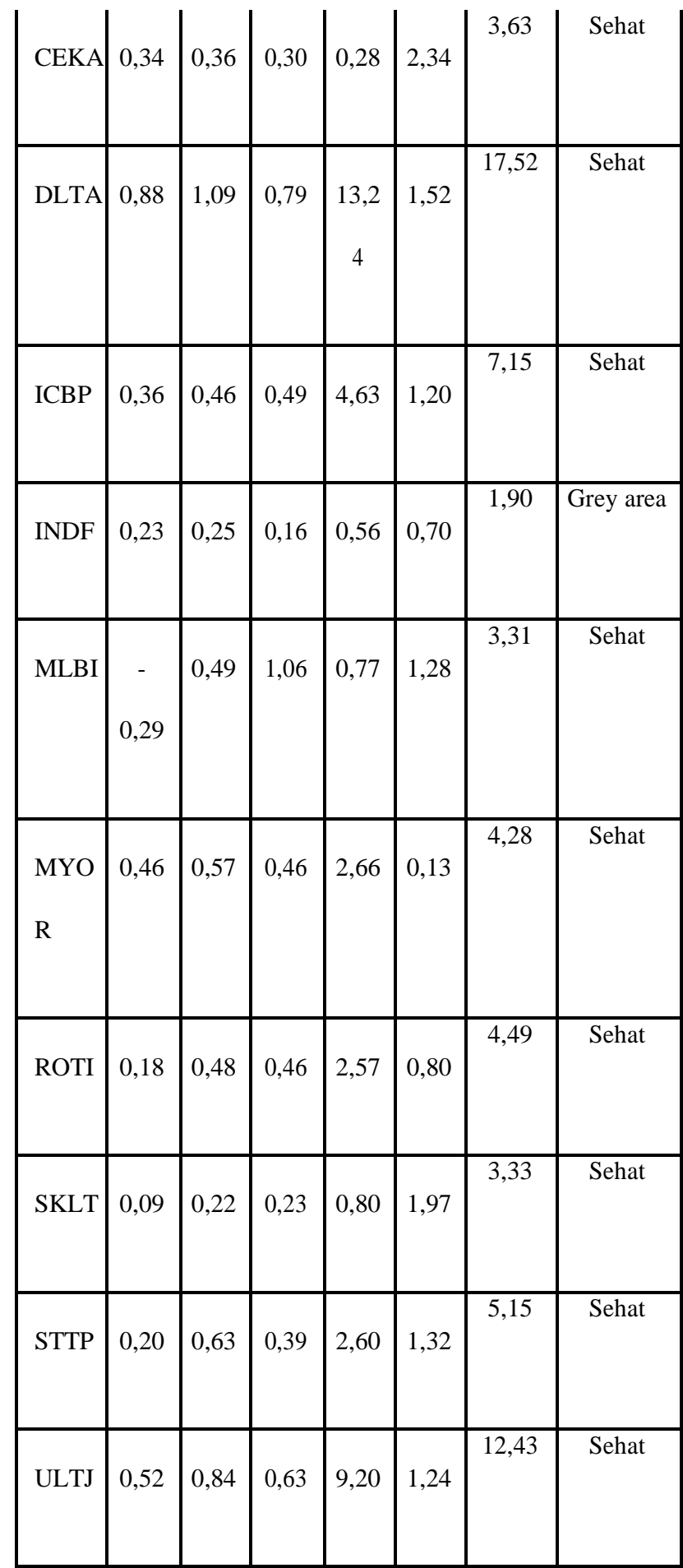

Sumber : Data sekunder diolah Mei 2018

Tabel 4.6.6

Hasil Z-Score Pada Perusahaan Makanan dan Minuman tahun 2016

\begin{tabular}{|c|l|c|c|c|c|c|c|}
\hline $\begin{array}{c}\text { Kode } \\
\text { Perusah } \\
\text { aan }\end{array}$ & X1 & X2 & X3 & X4 & X5 & Z- & Hasil \\
& & & & & & Score & Analisis \\
\hline AISA & 0,44 & 2,67 & 0,33 & 0,75 & 0,71 & 2,50 & Grey Area \\
\hline
\end{tabular}


ISSN : 2339-1510

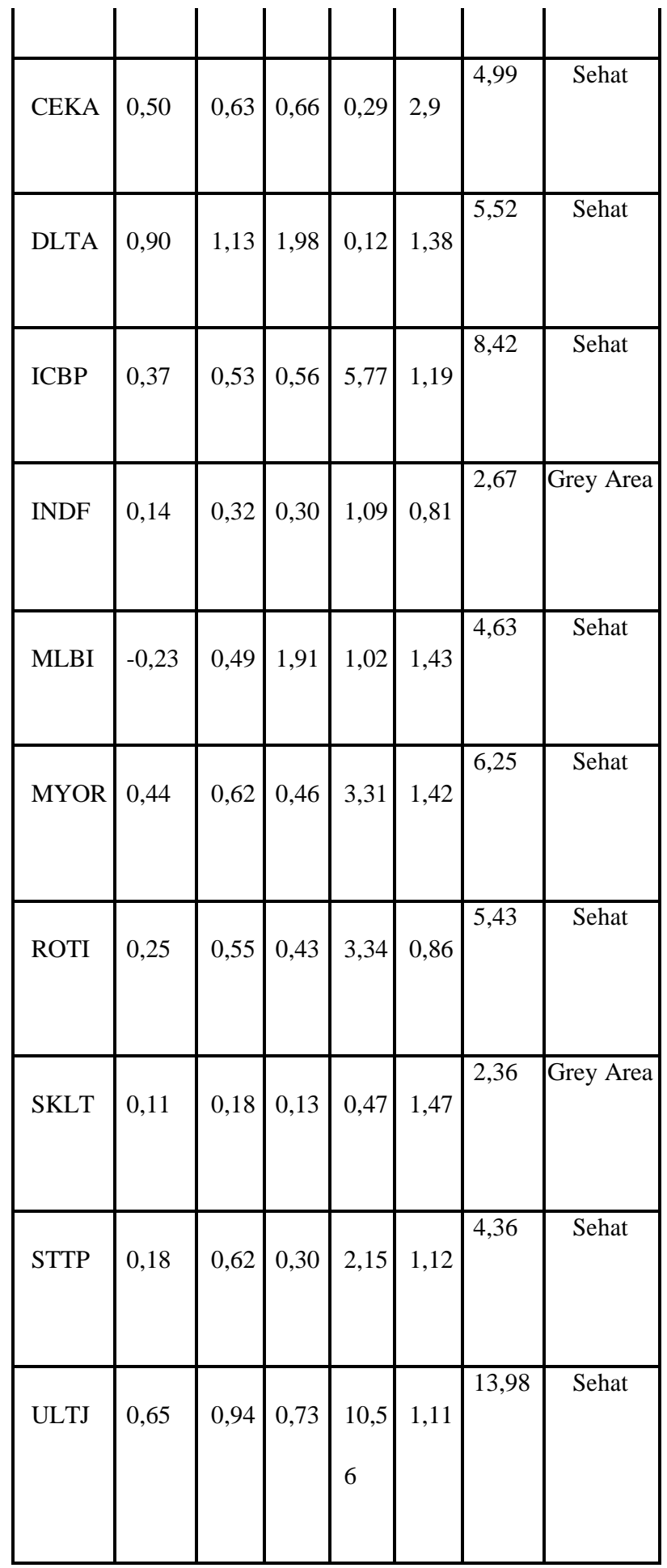

Sumber : Data sekunder diolah Mei 2018

Hasil analisis tersebut diatas menunjukkan prediksi kebangkrutan dengan menggunakan metode Altman Z-Score, sebagai berikut :

1. Hasil analisis metode Altman Z-score pada perusahaan makanan dan minuman pada tahun 2011 mengalami kondisi keuangan yang berbeda yaitu ada satu Perusahaan makanan dan minuman mengalami kondisi kebangkrutan yaitu AISA (PT. Tiga Pilar
Sejahtera Food, Tbk) dengan nilai Z-Score 1,48 atau $\mathrm{Z}<1,81$ sedangkan 10 perusahaan lainnya memiliki kondisi keuangan yang sehat dengan nilai Z-Score $>2,99$.

2. Pada tahun 2012 terdapat delapan perusahaan yang berada pada kondisi keuangan yang sehat yaitu perusahaan AISA, CEKA, DLTA, ICBP, MLBI, MYOR, STTP, dan ULTJ dengan nilai ZScore > 2,99 dan tiga Perusahaan berada pada kondisi Grey area ( daerah abu-abu) dengan nilai Z-Score antara 1,81 - 2,99 yaitu INDF (PT. Indofood Sukses Makmur, Tbk), ROTI (PT. Nippon Indosari Corpindo), SKLT (PT. Sekar Laut, Tbk)

3. Pada tahun 2013 dan 2014 terdapat dua perusahaan berada pada kondisi grey area (daerah abu-abu) dengan nilai Z-Score antara 1,81 - 2,99 yaitu AISA (PT. Tiga Pilar Sejahtera Food, Tbk) dan INDF (PT. Indofood Sukses Makmur, Tbk), sedangkan sembilan perusahaan lainnya berada pada kondisi sehat atau tidak mengalami kebangkrutan yaitu CEKA, DLTA, ICBP, MLBI, MYOR, ROTI, SKLT, STTP,ULTJ dengan nilai Z-Score > 2,99.

4. Pada tahun 2015 terdapat satu perusahaan berada pada kondisi bangkrut dengan nilai Z-Score < 1,81 yaitu AISA (PT. Tiga Pilar Sejahtera Pilar, Tbk), satu perusahaan berada pada kondisi grey area (daerah abu-abu) dengan nilai Z-Score antara 1,81 - 2,99 yaitu INDF (PT. Indofood Sukses Makmur, Tbk), sedangkan 10 (Sepuluh) lainnya berada pada kondisi sehat atau tidak mengalami kebangkrutan karena nilai Z-Scorenya > 2,99 yaitu CEKA, DLTA, ICBP, MLBI, MYOR, ROTI, SKLT, STTP, ULTJ.

5. Pada tahun 2016 ada sembilan perusahaan makanan dan minuman berada pada kondisi sehat dengan nilai Z-Score > 2,99 yaitu CEKA, DLTA, ICBP, INDF, MLBI, MYOR, STTP, ULTJ, sedangkan tiga lainnya berada pada kondisi grey area (daerah abu-abu) dengan nilai Z-Score antara 1,81 - 2,99 yaitu AISA (PT. Tiga Pilar Sejahtera Food, Tbk), INDF (PT. Indofood Sukses Makmur, Tbk) dan SKLT (PT. Sekar Laut, Tbk 
ISSN : 2339-1510

\section{SIMPULAN DAN SARAN}

\section{Simpulan}

Hasil analisis data dengan menggunakan metode Altman Z-Score mampu memprediksi kebangkrutan perusahaan makanan dan minuman yang terdaftar di Bursa Efek Indonesia periode 2011-2016, terdapat tujuh perusahaan berada pada kondisi keuangan yang sehat karena mencapai nilai Z-Score $\geq 2,99$. Perusahaan yang sehat keuangannya yaitu CEKA, DLTA, ICBP, MLBI, MYOR, STTP, dan ULTJ, sedangkan ada tiga perusahaan makanan dan minuman yang berada pada kondisi grey area (daerah abu-abu) dengan nilai Z-Score antara 1,81 - 2,99 yaitu INDF (PT. Indofood Sukses Makmur, Tbk), ROTI (PT. Nippon Indosari Corpindo, Tbk) dan SKLT (PT. Sekar Laut, Tbk) dan ada satu perusahaan makanan dan minuman yang berada pada kebangkrutan karena nilai Z-Score $\leq 1,81$

\section{Saran}

\section{Bagi Perusahaan}

Hasil analisis metode Z-Score menunjukkan bahwa pada perusahaan makanan dan minuman terdapat perusahaan yang mengalami ancaman kebangkrutan, oleh karena itu pihak manajemen perusahaan harus segera mengambil tindakan korektif atau pencegahan baik secara finansial maupun non finansial jika diketahui tingkat kesehatan keuangan perusahaan semakin menurun dan menunjukkan gejala kegagalan bisnis atau kebangkrutan.

2. Bagi peneliti selanjutnya

Untuk mengetahui dan menganalisis terhadap kondisi kebangkrutan perusahaan disarankan pada peneliti selanjutnya, sebaikanya tidak menggunakan satu jenis analisis, pemakaian beberapa model prediksi Kebangkrutan sebagai bahan perbandingan agar analisis yang dilakukan benar-benar akurat karena setiap model analisis kebangkrutan memiliki kelemahan dan kelebihan masing-masing.

\section{DAFTAR PUSTAKA}

Altman, Edward I. Ratio,Discriminant

1968. Financial analysis and the prediction of corporate Bankruptcy.the Journal of Finances.

Alim, Alif. $\quad$ F. 2017. AnalisisPrediksi kebangkrutan dengan metode Altman Z- Score pada perusahaan makanan dan minuman yang terdaftar di Bursa Efek Indonesia. Skripsi. Universitas Islam Indonesia.

Adnan, H. Arisudhana, D. "analisis kebangkrutan Model Altman Z-Score dan Springate pada perusahaan Industri Property". Jurnal. Jakarta : Fakultas Ekonomi Universitas Budi Luhur Jakarta.

Anggraini, Y. R. 2011. “Analisis Prediksi kebangkrutan perbankan berdasarkan metode Altman's Z-score pada PT. Bank Rakyat Indonesia(Persero), Tbk”.

Skripsi. Jember : Universitas Jember.

Brigham, Eugene F. Weston, J.F. 2011. Dasar Dasar Manajemen Keuangan Edisi 11 buku 2. Salemba 4. Jakarta.

Brimantyo, Dkk. 2013. "Penerapan analisis Altman Z-Score sebagai salah satu alat untuk mengetahui kebangkrutan perusahaan pada perusahaan Telekomunikasi yang listing di BEI periode 2009-2011. Jurnal. Universitas Brawijaya.

Darsono. 2004. Manajemen Perusahaan Indonesia. Jakarta. Rineka Cipta.

Endri.2009. "PrediksiKebangkrutan

Bank untuk menghadapi dan Mengelolah Perubahan Lingkungan Bisnis: Analisis Model Altman's Z-Score. Perbanas Quarterly Review, 2(1).

Fatmawati, M. 2012. "penggunaan the Zmijwski model, the Altman model dan the Springate model sebagai prediktor delisting". Jurnal Administrasi bisnis $(J A B)$. Vol. 28. No. 1.

Febrianasari, H.N. 2012. "Analisis penilaian financial distress menggunakan model Altman (Z-Score) pada perusahaan kosmetik yang tercatat di Bursa Efek Indonesia. E-Jurnal Akuntansi. Universitas Negeri Surabaya. Vol. 1 No. 1. 
Ferdila, R. 2016. “ Prediksi kebangkrutan dengan metode Altman Z-Score pada perusahaan pulp \& kertas yang terdaftar di Bursa Efek Indonesia (periode 2011 2015)”. Skripsi. Universitas Katolik Soegijapranata.

Fitrikah, L. 2013. "Analisis penggunaan Metode Z-Score Altman untuk memprediksi potensi Kebangkrutan Perusahaan Perbankan Go public di Bursa Efek Indonesia periode 20092011. Skripsi. Malang. Universitas Islam Negeri Maulana Malik Ibrahim.

Harnanto. 2007. “Analisa Laporan keuangan. Yokyakarta: UUP AMP YKPN.

Hanafi, M. M. 2014. Manajemen Keuangan. Cetakan Ke-7. Yokyakarta: BPFE.

Kasanah, S. N. 2015. “Analisis Z-Score Altman pada perusahaan Makanan dan Minuman yang terdaftar di Bursa Efek Indonesia (BEI) periode 2012-2014. Proposal skripsi. Kediri. Universitas Nusantara PGRI Kediri.

Kasmir. 2008. "Analisis Laporan Keuangan”. Jakarta. Rajawali Pers

Kamal, ST. Ibrah M. 2012. “Analisis Prediksi Kebangkrutan Pada Perusahaan Perbankan Go Public di Bursa Efek Indonesia (dengan menggunakan metode Altman Z-Score). Skripsi. Makassar. Universitas Hasanuddin.

Karina, S. D. 2014. "Prediksi Kebangkrutan pada Perusahaan Media yang terdaftar diBursa Efek Indonesia".Laporan Akhir. Palembang. Politeknik Negeri Sriwijaya.

Kneefel, S.A. Mandagie, Y. 2015. "Analisis ZScore pada perusahaan food \& beverage yang terdaftar di BEI periode 2011-2013. Jurnal EMBA. Vol. 3. No.3 (diakses September 2015)

Nugroho, Mokhamad I. D. 2012. AnalisisFinancial Distress dengan menggunakan Model Altman ZScore Modifikasi 1995 (Studi kasus pada Perusahaan Manufaktur yang Go Public di Indonesia tahun 2008 sampai dengan tahun 2010). Skripsi. Semarang. Universitas Diponegoro

Muflifah, T. 2017. "Penggunaan metode Altman Z-Score untuk memprediksi kebangkrutan pada perusahaan food \& beverage yang terdaftar di Bursa Efek Indonesia". Jurnal. Universitas PGRI Yokyakarta.

Mar'ati, N. Suhadak. Rustam, H. 2014. “ Implementasi penggunaan metode Altman (Z-Score) untuk menganalisis Estimasi Kebangkrutan (Studi pada PT. Bursa Efek Indonesia periode 20112013)". Jurnal Administrasi Bisnis. Universitas Briwijaya. Vol. 16. Nomor 1 Mei 2014.

Munawir, S. 2002. Analisis Informasi Keuangan. Liberty. Yokyakarta.

Prihadi, Toto. $2011 . \quad$ "Analisis Laporan Keuangan konsep dan aplikasi”. Jakarta : PPM Manajemen.

Perwira, G. S. “Analisis Metode Z-Score untuk memprediksi kebangkrutan Industri Baja di BEI”. Artikel. Universitas Gunadarma.

Putro, B. A. 2009. "Analisis Rasio keuangan dengan metode Altman Z-Score untuk memprediksi potensi kebangkrutan perusahaan (studi kasus pada PT. PURA BARUTAMA Kudus). Skripsi. Surakarta. Universitas Muhammadiyah Surakarta.

Riyanto, B. 2001. Dasar-dasar Pembelajaran Perusahaan. Yogyakarta. BPFE. Sagho, M. F. Merkuisiwati, N. K. L. A. 2015. Pengunaan Metode Altman Z-score Modifikasi untuk memprediksi kebangkrutan bank yang terdaftar di Bursa Efek Indonesia". Jurnal. Bali. Universitas Udayana.

Sapar. "Pengantar Metode Penelitian. Cetakan ketiga. Bogor : Makairaa Printing Plus.

Siska, J. 2013. “Analisis tingat kebangkrutan dengan menggunakan metode Altman ZScore, Springate, dan internal Growth Rate pada PT. BUMI Resources Tbk. Periode 2008-2012. Skripsi. Riau. Universitas Islam Negeri Sultan Syarif Kasim Riau. 
ISSN : 2339-1510

Sugiyono. 2008. "Metode Penelitian Bisnis. Bandung : Alfabeta.

Wulandari, F. Burhanuddin,. dkk. "Analisis Prediksi Kebangkrutan menggunakan Metode Altman (Z-Score) pada Perusahaan Farmasi (Studi kasus pada Perusahaan yang terdaftar di Bursa Efek Indonesia taun 2011-2015). Jurnal Manajemen dan Bisnis: Vol. 2 No. 1 (diakses pada tanggal 1 Juni 2017).

Yulia, A. 2013. "Analisis Kebangkrutan metode Altman Z-score pada perusahaan rokok Go Public. Jurnal. Surabaya. Sekolah Tinggi Ilmu Ekonomi Indonesia (STIESIA) Surabaya.

www.idx.co.id

www.sahamok.com 